\section{All to do with genes}

\section{Graham Boulnois}

Genetic Elements In Escherichla coll. By Peter Smith-Kleary. Macmillan, London: 1988. Pp.198. Hbk £25; pbk £9.95. To be published in the United States by Guilford, New York; price has yet to be decided.

Genetic Engineering. By J.G. Williams and R.K. Patient. IRL: 1988. Pp.72. PbK £5.95, \$11.95.

Gene Structure and Transcription. By T. Beebee and J. Burke. IRL:1988. Pp.77. Pbk £5.95, \$11.95.

Genetic Englneering: An Introduction to Gene Analysis and Exploitation In Eukaryotes. By S.M. Kingsman and A.J. Kingsman. Blackwell Scientific: 1988. Pp.522. Hbk £39.50, \$89; pbk £19.50, $\$ 43.95$.

THE techniques of molecular biology were largely developed for the genetic analysis of $E$. coli and its phages and plasmids, but rapidly found application in studies of the structure and function of eukaryotic genomes. The result has been not only an explosion in our understanding of gene organization and expression in higher organisms, but also the appearance of ever more powerful methods with application in prokaryotes and eukaryotes. Students therefore ought to acquire a solid background in both prokaryotic and eukaryotic molecular biology, yet the two branches are often treated as independent entities. In their different ways (but with the possible exception of Gene Structure and Transcription) these books continue to promote the divide. That said, both teacher and student will find much to interest them here.

The biological basis of recombinant DNA technology is well documented by Smith-Kleary. He discusses in detail the often-forgotten classical $E$. coli genetics which played such a crucial role in defining systems - such as the lac operon, phage lambda and plasmids - that are now the cornerstone of modern molecular biology. The combination of classical bacterial genetics and modern molecular genetics to be found in the book will fascinate those brought up on bacterial genetics. The problem-solving approach to the topic will be welcomed by many teachers, but may be received with less enthusiasm among 'technologically minded' students. The power and elegance of the classical genetics complements and contrasts with the more straightforward molecular genetics, and this is a good text for those wanting to look back upon the development of genetic engineering. But I wonder whether it will have a NATURE · VOL $338 \cdot 9$ MARCH 1989 place in a modern molecular biology course, where teaching time is at a premium.

The IRL "In Focus" series continues with Genetic Engineering and Gene Structure and Transcription. Both maintain the excellent record of these volumes, which are cheap, up-to-date, and provide clear and concise views of rapidly expanding fields. Of the two I found Beebee and Burke's Gene Structure and Transcription more interesting and informative - it provides a wealth of information on gene expression in both prokaryotes and eukaryotes, and well illustrates the power of the analytical methods concerned. Second- and third-year undergraduates would do well to acquire it.

In Genetic Engineering, Williams and Patient take a rather traditional approach (if this is possible in such a new field) to the description of how to clone and characterize genes. Much of the material can be found in other, more comprehensive texts, but the new approaches to cloning and analysis are made especially comprehensible with the aid of clear illustrations. To complement more biologically based texts, and as a revision aid, this book will be useful.

As an illustration of how genetic engineering can be exploited to probe basic

problems in biology, and of how it finds application in biotechnology, the text by Kingsman and Kingsman is excellent. The authors go beyond the isolation and characterization of genes and take the view, quite rightly, that manipulation of cloned genes and their reintroduction into cells is at the heart of things. The techniques, their application to biological systems as diverse as yeast and mammals, and their use in the analysis of processes ranging from photosynthesis to carcinogenesis, are clearly described and critically assessed. The figures, too, are good. This text will be widely used by final-year students, and many graduate students will find it a useful source of background information.

Given that there are now a great many textbooks on molecular biology and genetic engineering in competition for the student's money, in a sense it is sad to report that none of these books can be ignored. Each of the first three has its specialist niche, while Kingsman and Kingsman will find a place in supporting more general courses.

Graham Boulnois is a Lister Institute-Jenner Research Fellow and Reader in the Department of Microbiology, University of Leicester, Medical Sciences Building, Leicester LE1 9HN, UK.

\section{Figuring it out}

\section{Simon Hunt}

Complement. By S.K.A. Law and K.B.M. Reid. IRL:1988. Pp.72. PbK £5.95, $\$ 11.95$.

Lymphokines. By A.S. Hamblin. IRL:1988. Pp.71. Pbk £5.95, \$11.95.

Immune Recognition. By M.J. Owen and J.R. Lamb. IRL:1988. Pp. 73. Pbk £5.95, $\$ 11.95$.

Essentlal Immunogenetics. By A.R. Williamson and M.W. Turner. Blackwell Scientific:1988. Pp.432. Pbk £19.50, $\$ 46$.

DAVID Male, editor of the immunology titles in IRL's "In Focus" series, is a formidable optician. Between them, he and his authors write clearly, present the truth without gloss and bamboozle rarely. The first three of the series succeed authoritatively in making some fast-moving areas accessible and bang up to date. The format is attractive, with fresh two-colour diagrams, and occasional spectacular electron micrographs or full-colour graphics, and there are plenty of references. The amount of experimental description is well balanced. All of the authors finish by peering enthusiastically into the future.

Complement could easily have been the customary catalogue, but Law and Reid's account is a revelation, integrating the kick-off of the two pathways, the control mechanisms and the fascinating molecular homologies $(\mathrm{C} 1 \mathrm{q}$ with collagen; the serine proteases; the perforins with terminal attack-proteins; the short consensus repeats) with the consequences for pathological processes. You might think that every possible representation of the pathways has been tried, but I have not seen it done better than in Fig. 1.1 of this book.

Likewise, in Lymphokines Hamblin uses her first diagram for crisp scenesetting. For each of the interleukins 1 to 6 , gamma interferon and the cytokines acting on the various haemopoietic compartments, she covers methodology, biochemistry, some genetics and their in vitro properties, ending with some possible clinical applications. Immune Recognition, however, was perhaps allowed to stray too far. In this case Fig. 1.1 shows MHC restriction in $\mathbf{T}$-cellmediated cytotoxicity; Owen and Lamb then shoot through immunoglobulin, $\mathrm{MHC}$ antigen and T-cell-receptor structure, function and gene diversification, and just squeeze in a section on thymocyte maturation. It's all a bit fast and dense.

Picking off areas one by one is of course what students and their tutors usually do, but with the eventual penalties of some overlap and of loss of broad perspective. So there is still a place for a good general textbook. Might Essential Immunogenetics do the job? The authors seek to make their subject more approachable to new- 